\title{
Effect of Process Parameters on Repeatability Precision of Weight for Microinjection Molding Products
}

\author{
Quan Wang (D), Jinrong Wang, ${ }^{1}$ Chongying Yang, ${ }^{1}$ Kaihui Du, \\ Wenli $\mathrm{Zhu}^{2}$, and Xiaoli Zhang ${ }^{3}$ \\ ${ }^{1}$ National Local Joint Engineering Laboratory of Intelligent Manufacturing Oriented Automobile Die \& Mold, \\ Tianjin University of Technology and Education, Tianjin 300222, China \\ ${ }^{2}$ School of Mechanical \& Automobile Engineering, Hubei University of Arts and Science, Hubei 441053, China \\ ${ }^{3}$ College of Materials Science and Engineering, Zhengzhou University, Henan 450001, China
}

Correspondence should be addressed to Quan Wang;wq2001126@163.com

Received 19 March 2019; Revised 3 May 2019; Accepted 16 May 2019; Published 4 June 2019

Guest Editor: Peng Zhao

Copyright (C) 2019 Quan Wang et al. This is an open access article distributed under the Creative Commons Attribution License, which permits unrestricted use, distribution, and reproduction in any medium, provided the original work is properly cited.

\begin{abstract}
The repeatability precision of weight for injection molded products is important technical parameter to measure the quality and accuracy of injection molded products and evaluate the performance of injection molding machine. The influence of mold temperature, melt temperature, packing pressure, and packing time on the weight of microinjection molding products was studied by Taguchi orthogonal experiment. The influence of peak cavity pressure on the weight of products also was analysed. The experimental results show that the packing pressure is the most important process parameter affecting both the weight of the tensile and the impact specimens. With the increase of the packing pressure, the weight of the tensile and the impact specimens increases. When the peak cavity pressure reaches a certain value, the pressure value of the tensile specimen is $65 \mathrm{MPa}$, and the pressure value of the impact specimen is $68 \mathrm{MPa}$, the weight of the product increases quickly. The packing pressure increased from $85 \mathrm{MPa}$ to $100 \mathrm{MPa}$, the weight of the tensile specimen increased from $0.544 \mathrm{~g}$ to $0.559 \mathrm{~g}$, an increase of $2.7 \%$, and the weight of the impact specimen increased from $0.418 \mathrm{~g}$ to $0.425 \mathrm{~g}$, an increase of $1.7 \%$.
\end{abstract}

\section{Introduction}

With the development of the synthesis and molding technology of polymer materials, more and more polymer precision products are applied to the advanced technology fields such as aerospace, medical instruments, biological engineering, precision optics, electronic communication, and so on [15]. More than $90 \%$ of the plastic molding products are the two main molding methods in the process of polymer molding, extrusion molding, and injection molding. This puts forward higher requirements for the quality precision of the polymer molding products, and the research on the factors affecting the quality precision and how to evaluate the quality of the molded products scientifically and effectively is the precondition of improving the precision of the molding quality.

Plastic injection molding is a widely used and complex process and is a highly efficient technique for producing a large quantity of plastic products, with high production requirement and tight tolerance. It is well-known as the manufacturing technique to produce products with various shapes and complex geometry at low cost [6-8]. The quality of parts produced by injection molding is a function of plastic material, part geometry, mold structure, and process conditions $[9,10]$.

The repeatability accuracy of injection molded products includes three aspects, such as size, appearance, and injection weight. It can measure the quality and accuracy of injection products [11-14]. However, the size and appearance of the products are different because of different products shape. It cannot be used to realize the quantitative comparison of the performance of different products and different machines. Therefore, the repetition precision of injection weight is usually used as a technical index to measure the quality accuracy of injection products and evaluate the performance of the injection molding machine [15]. The weight repetition 
precision of the ordinary injection molding machine is about $1 \%$, which can reach $0.8 \%$. The precision injection machine is lower than $0.5 \%$, and the highest international level is less than $0.15 \%$ at present [16]. The improvement of the repetition precision of injection weight depends on the accuracy of mold processing and the rationality of the structure design, the performance of the raw materials, the rationality of the process parameters, and the control performance of the machine $[17,18]$. Therefore, it is instructive for improving the repetition accuracy of injection weight to study the process parameters affecting the injection weight and the algorithm of repetition accuracy of injection weight which conforms to the characteristics of injection molding.

\section{Calculation Method}

The injection weight is the weight of the polymer melt from the nozzle of injection molding machine. The conventional injection weight based on the injection volume control method is related to the diameter of the injection screw and the injection stroke. The theoretical calculation formula is such as (1).

$$
\begin{aligned}
\mathrm{W} & =\delta \frac{\pi}{4} \mathrm{D}_{\mathrm{s}}^{2} \mathrm{~S} \rho=\mathrm{V}_{\mathrm{a}} \rho \\
\mathrm{V}_{\mathrm{a}} & =\delta \frac{\pi}{4} \mathrm{D}_{\mathrm{s}}^{2} \mathrm{~S}
\end{aligned}
$$

where $W$ is the injection weight, $g$; $\rho$ is density of polymer resin in room temperature, $\mathrm{g} / \mathrm{cm}^{3} ; D_{s}$ is the diameter of the screw, $\mathrm{cm}$; $S$ is the stroke of screw, $\mathrm{cm} ; V_{a}$ is actual injection capacity, $\mathrm{cm}^{3} ; \delta$ is injection coefficient, which varies with different raw materials.

In (1), the diameter $D_{s}$ of the screw is given by the injection machine and $\delta$ is the empirical coefficient. The injection stroke $S$ of the screw is accurately measured by the displacement sensor and controlled by the servo motor driving the ball screw; that is to say, $V_{a}$ is kept constant. In the traditional injection volume control method, $\rho$ is a constant value. The injection weight obtained from (1) is the weight of the injection product. However, in the actual injection process, $\rho$ is not really constant. The change rate of melt density of polypropylene (Trademark T30S, MFR=3.2g/10min, supplied by Mao Ming Phoenix Ltd., China) is $6.44 \%$ when the pressure rises from $2 \mathrm{MPa}$ to $30 \mathrm{MPa}$ in temperature $190^{\circ} \mathrm{C}$. When the temperature is $200^{\circ} \mathrm{C}$, the change rate of polypropylene under the same pressure is 6.64\% [19]. Therefore, the injection weight obtained by formula (1) is not the real weight of the injection molded product. Of course, the traditional volume control method cannot achieve the consistency of weight of injection products. According to the control technology of PVT in the injection process, the molding process, especially the temperature and pressure, has an important influence on the polymer melt $\rho[20,21]$. Therefore, the effect of molding process on the injection weight accuracy of microinjection molding products is studied in this paper.

Repetitive precision refers to the degree of consistency between the results of continuous measurements of the same object under the same measurement conditions. It is the degree of repetition error in the measurement results. Therefore, the repetition accuracy of injection weight can be understood as the consistency between the weight of injection molded parts and the ideal weight of injection molded parts, which is a concept based on statistical process. There are two formulas for calculating the weight repeatability of products which are given as follows:

$$
\begin{aligned}
& \delta_{\mathrm{G}}=\frac{\mathrm{w}_{\max }-\mathrm{w}_{\min }}{\overline{\mathrm{w}}} \times 100 \% \\
& \delta_{\mathrm{G}}=\frac{\sqrt{(1 /(\mathrm{n}-1)) \sum_{\mathrm{i}=1}^{\mathrm{n}}\left(\mathrm{w}_{\mathrm{i}}-\overline{\mathrm{w}}\right)^{2}}}{\overline{\mathrm{w}}} \times 100 \% \\
& \overline{\mathrm{w}}=\sum_{\mathrm{i}}^{\mathrm{n}} \frac{\mathrm{w}_{\mathrm{i}}}{\mathrm{n}}
\end{aligned}
$$

where $n$ is the number of sample products; $w_{i}$ is the weight of the i product, $g$; $w_{\max }$ is the maximum weight of the product, $g ; w_{\min }$ is the minimum weight of the product, $g$; $\bar{w}$ is the average weight of the sample, g; $\delta_{G}$ is the repetition precision of the product weight.

The denominators of (2) and (3) denote the arithmetic average weight of the sample product, and the numerator denotes the fluctuation of the sample data. Equation (2) is the sample range; and (3) is the sample standard deviation. Therefore, (2) is the polar difference algorithm, and (3) is the standard deviation algorithm. In order to objectively calculate the weight repetition accuracy of the products and eliminate the influence of abnormal values, (3) is chosen in the paper.

\section{Experimental}

3.1. Materials. The sample material used in this work was polypropylene in the form of pellets and with a trade mark $5090 \mathrm{~T}$ (MFI=15g/10min), supplied by the Formosa petrochemical Corp, Taiwan.

3.2. Microinjection Molding Machine. The experimental work was carried out on an injection molding machine of type BOX XS concept having a maximum injection pressure 2298 bar, with screw diameter for plastication $14 \mathrm{~mm}$ and maximum weight of the product 6.1g as shown in Figure 1.

3.3. Mold. The multispline injection mold constructed from two parts (tensile specimen and impact specimen). The mold cavity thickness is $1 \mathrm{~mm}$. The cavity pressure and temperature is measured in the mold cavity by the quartz sensor for mold cavity pressure type Kistler 6190CA, which has a front of $4.0 \mathrm{~mm}$ diameter. Data output from the amplifier is collected using a Kistler 5865 Como injection system. Computer is used to record the output reading of the acquisition system through an interface cart by the help of lab view program. The pressure sensors are installed in the middle of the specimens, respectively. The distance from the gate is $8 \mathrm{~mm}$. The dimensions of specimen and gate are shown in Figure 2.

3.4. Mold Temperature Controller. The mold temperature controller (model TP6ZE) was adopted using PIOVAN Co. Ltd., Italia. 


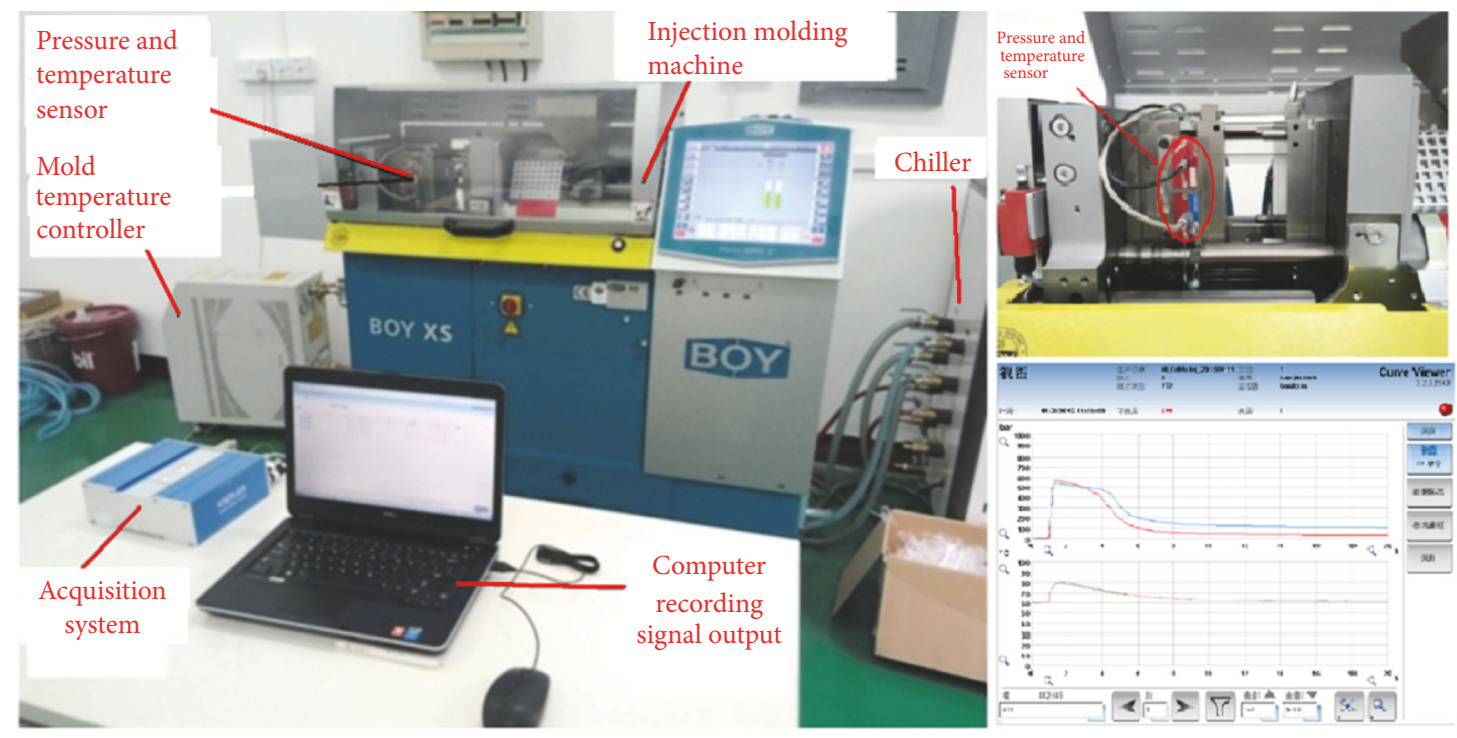

FIgURE 1: Experimental setup.

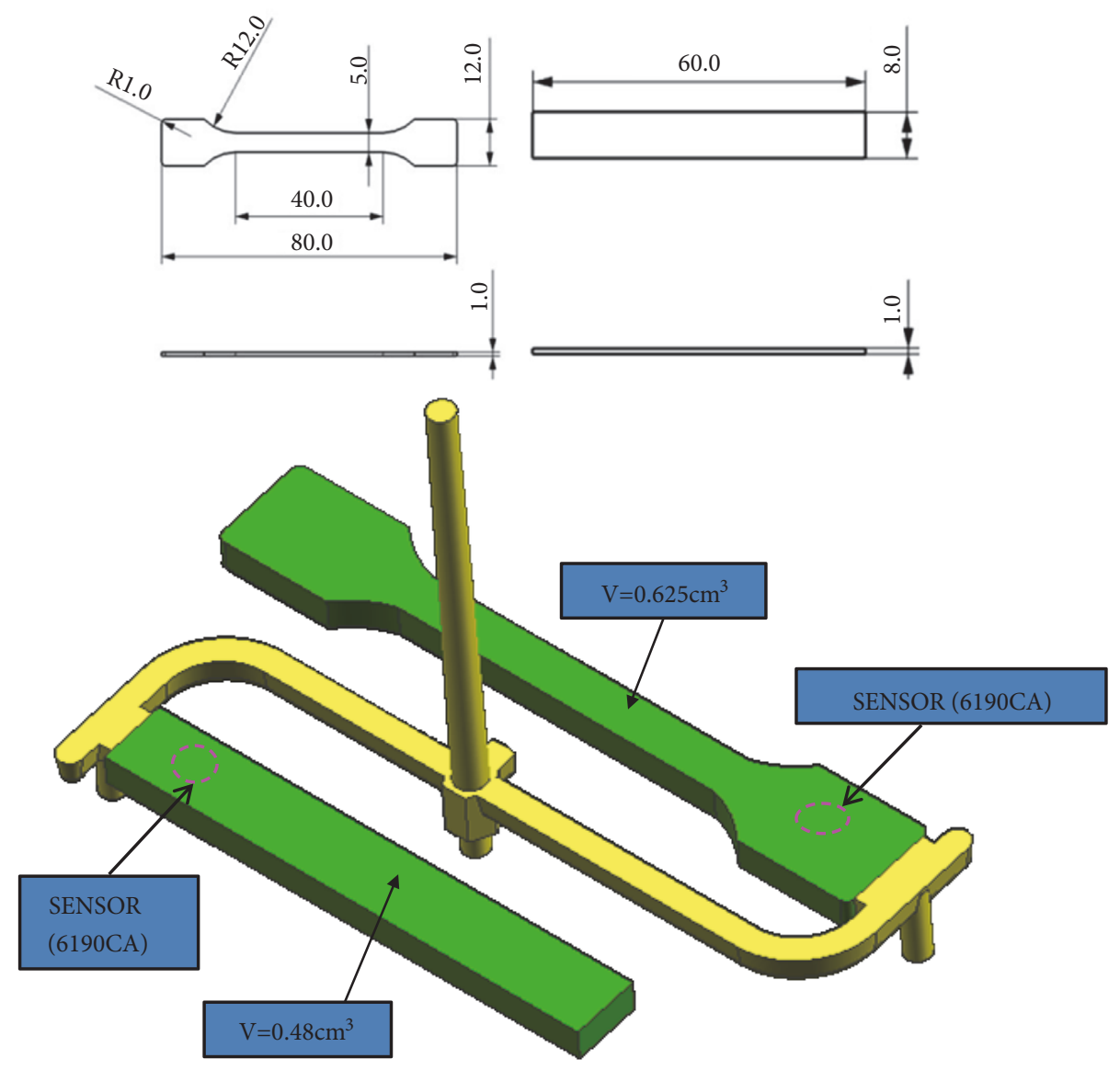

FIGURE 2: Dimension of specimen and gate. 
TABLE 1: Parameters of injection molding process.

\begin{tabular}{lccccc}
\hline Level & $\begin{array}{c}\text { melt temperature } \\
\left({ }^{\circ} \mathrm{C}\right)\end{array}$ & $\begin{array}{c}\text { mold temperature } \\
\left({ }^{\circ} \mathrm{C}\right)\end{array}$ & $\begin{array}{c}\text { Packing pressure } \\
(\mathrm{MPa})\end{array}$ & $\begin{array}{c}\text { Packing time } \\
(\mathrm{s})\end{array}$ & $\begin{array}{c}\text { Injection pressure } \\
(\mathrm{MPa})\end{array}$ \\
\hline 1 & 220 & 40 & 85 & 5 & 85 \\
2 & 230 & 50 & 90 & 10 & 90 \\
3 & 240 & 60 & 95 & 15 & 20 \\
4 & 250 & 70 & 100 & 20 & 100 \\
\hline
\end{tabular}

3.5. Chiller. Chiller (model ML-CA03) was adopted Ming Lee Co. Ltd., Hong Kong, China.

3.6. Electronic Balance. Electronic balance (model CP214) was adopted OHAUS Co. Ltd., America. The accuracy is $0.1 \mathrm{mg}$.

Melt temperature, mold temperature, packing pressure, packing time, and injection pressure were chosen as the process parameters. Parameters of injection molding process are reported in Table 1.

Orthogonal design is a high-efficiency design method for tests to arrange multifactor tests and seek optimal level combinations. The design method of orthogonal tests is able to determine optimal parameters by simply calculating influences of each factor on test results, showing the influences in charts, and then comprehensively comparing differences. The calculation is carried out on orthogonal tables, so the whole process is simple and clear. In this way, enough information can be obtained through a few tests, thus saving costs. An $\mathrm{L}_{16}\left(4^{5}\right)$ orthogonal array was selected for the experimental design for each of the five factors. The four levels for the five parameters were identified during the 16 experiments. The data of injection five molds were recorded under the same conditions and the peak cavity pressure also was recorded. Then, the process parameters were changed to continue the same procedures. The values of these parameters are presented in Table 2.

\section{Results and Discussion}

The variance analysis of the relationship between the specimen weight and the process parameters was carried out, in which A stands for melt temperature $\left({ }^{\circ} \mathrm{C}\right)$, B stands for mold temperature $\left({ }^{\circ} \mathrm{C}\right), \mathrm{C}$ stands for packing pressure $(\mathrm{MPa})$, $\mathrm{D}$ stands for packing time (s), and $\mathrm{E}$ stands for injection pressure $(\mathrm{MPa})$. Figure 3 shows that the packing pressure, mold temperature, and melt temperature have great influence on the weight of the product, while the packing time and injection pressure have little influence on the weight of the product.

The weight of the tensile and impact specimens increases with the increase of the melt temperature as illustrated in Figure 4 . The weight of the tensile specimen increases faster than that of the impact specimen in the melt temperature range of $230^{\circ} \mathrm{C}$ to $240^{\circ} \mathrm{C}$. When the melt temperature rises from $220^{\circ} \mathrm{C}$ to $250^{\circ} \mathrm{C}$, the weight of the tensile specimen increases from $0.548 \mathrm{~g}$ to $0.554 \mathrm{~g}$, by $1.1 \%$. The weight increased from $0.419 \mathrm{~g}$ to $0.423 \mathrm{~g}$, an increase of $0.9 \%$ for the impact specimen.
TABLE 2: Proposed $\mathrm{L}_{16}$ orthogonal array.

\begin{tabular}{llllll}
\hline Level & A & B & C & D & E \\
\hline 1 & 1 & 1 & 1 & 1 & 1 \\
2 & 1 & 2 & 2 & 2 & 2 \\
3 & 1 & 3 & 3 & 3 & 3 \\
4 & 1 & 4 & 4 & 4 & 4 \\
5 & 2 & 1 & 2 & 3 & 4 \\
6 & 2 & 2 & 1 & 4 & 3 \\
7 & 2 & 3 & 4 & 1 & 2 \\
8 & 2 & 4 & 3 & 2 & 1 \\
9 & 3 & 1 & 3 & 4 & 2 \\
10 & 3 & 2 & 4 & 3 & 1 \\
11 & 3 & 3 & 1 & 2 & 4 \\
12 & 3 & 4 & 2 & 1 & 3 \\
13 & 4 & 1 & 4 & 2 & 3 \\
14 & 4 & 2 & 3 & 1 & 4 \\
15 & 4 & 3 & 2 & 4 & 1 \\
16 & 4 & 4 & 1 & 3 & 2 \\
\hline
\end{tabular}

Figure 5 shows the effect of mold temperature on the weight of the product. The weight of the tensile specimen increases with the increase of mold temperature, but the impact specimen shows the opposite situation. This may be due to the filling unbalance of the two mold cavities because of different dimensions and weight of product. The cavity of impact specimen is filled before the tensile specimen, resulting in a large residual stress and shrinkage. In molding process, reasonable adjustment of process parameters should be made to achieve the best balance filling of two cavities. The weight of tensile specimen increased from $0.544 \mathrm{~g}$ to $0.551 \mathrm{~g}$, an increase of $1.3 \%$, and the weight of impact specimen decreased from $0.422 \mathrm{~g}$ to $0.420 \mathrm{~g}$, a decrease of $0.47 \%$. The increase of mold temperature can promote the filling of melt, the specimen is more compact, the melt fluidity will be guaranteed, and the mechanical properties of the specimen are improved.

Figure 6 is the effect of packing pressure on the weight. The weight of tensile and impact specimens increases with the increase of packing pressure, which is due to the increase of packing pressure, filling more melt in the cavity at the same time, the specimen is more compact, but excessive packing pressure will cause stress of products. The packing pressure increased from $85 \mathrm{MPa}$ to $100 \mathrm{MPa}$, the weight of tensile specimen increased from $0.544 \mathrm{~g}$ to $0.559 \mathrm{~g}$, an increase of $2.7 \%$, and the weight of impact specimen increased from $0.418 \mathrm{~g}$ to $0.425 \mathrm{~g}$, an increase of $1.7 \%$. 


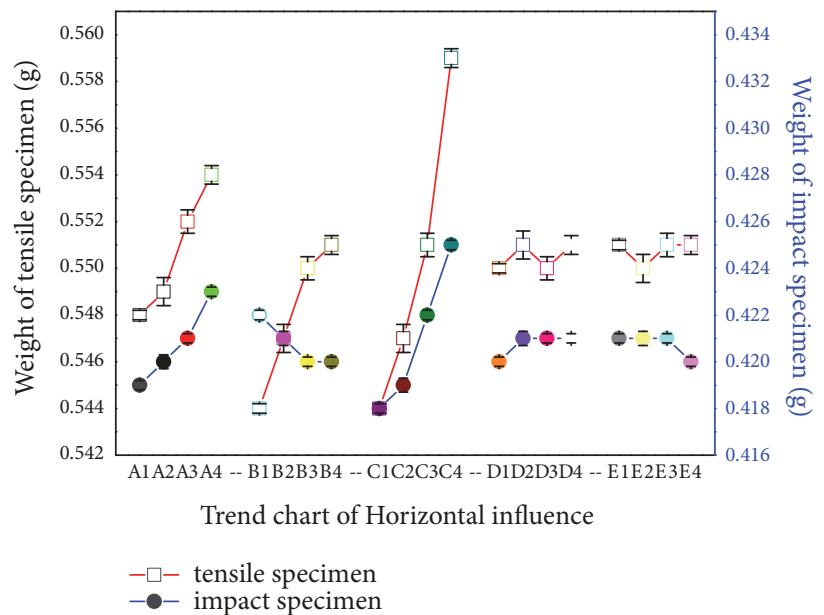

FIGURE 3: Horizontal trend chart of tensile and impact specimen.

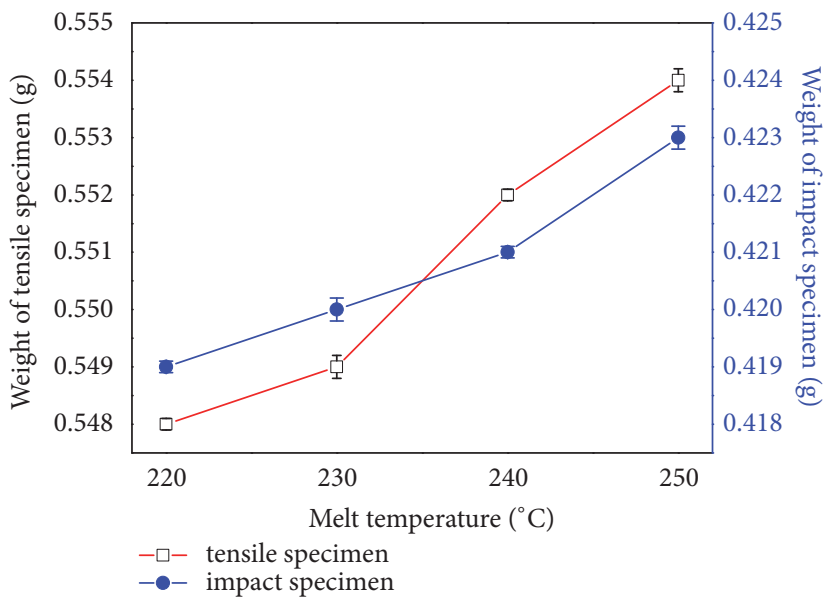

FIGURE 4: Influence of melt temperature on product weight.

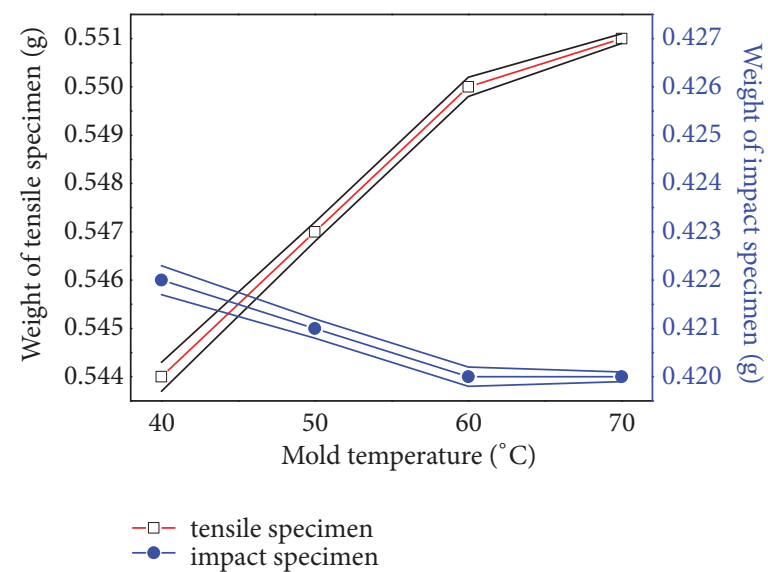

FIGURE 5: Influence of mold temperature on product weight.

Influence of packing time on product weight is illustrated in Figure 7. The packing time has little effect on the weight of the product, indicating that when the product is small, the gate has cooled, and increasing the packing time has little effect on the weight of the product.
Because the filling process of the cavity is not known in the molding process, the weights of the parts become important basis for verifying the defects of parts. In the process of injection molding, the pressure is not large enough to fill the cavity; short shots and other phenomena will 


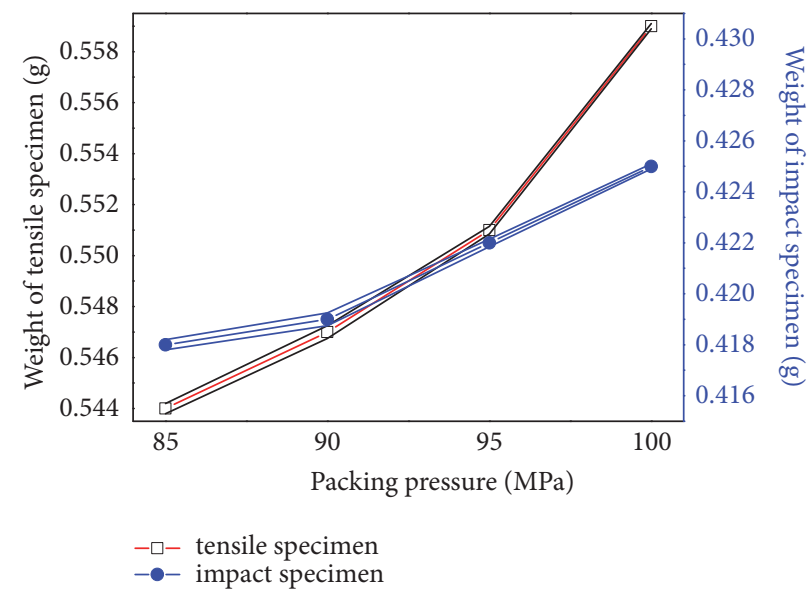

FIGURE 6: Influence of packing pressure on product weight.

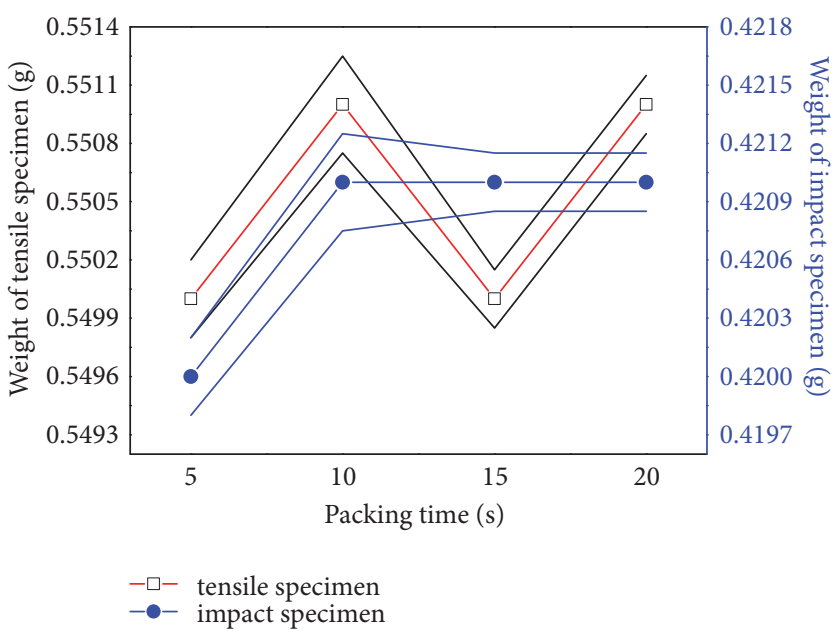

FIGURE 7: Influence of packing time on product weight.

occur. Injection molding pressure is one of the key processing parameters mentioned in several research works [22-25]. The peak cavity pressure and product weight have a certain relationship. Because the cavity pressure curve records the change of cavity pressure during the whole injection molding process, the relationship between them is studied to guide the production better.

The weight of the tensile and impact specimen increases with the increase of the peak cavity pressure as illustrated in Figure 8 . This is because the larger the peak cavity pressure, the better the fluidity of melt, the more the melt injected into the cavity at the same time, and the greater the density of the specimen. At the same time, the weight of the specimen does not increase significantly before the cavity pressure reaches $65 \mathrm{MPa}$ for tensile specimen. After the peak pressure reaches $65 \mathrm{MPa}$, the weight increases rapidly. The peak cavity pressure increases; the more melt is filled into the cavity in the same time. The density of specimen is enhanced, and the weight of the specimen increases. The pressure continues to pack in additional material which is low in viscosity. Therefore, the less viscous melt is able to fill up the cavity thoroughly and even created some flash without causing significant increase in pressure. Due to the fact that more material is in the cavity, the parts produced are heavier and denser although peak cavity pressure does not increase much. The maximum weight of impact specimen appears about $71 \mathrm{MPa}$. Because the peak cavity pressure has a high correlation with the weight of specimen, the pressure value and the actual parts can be recorded in actual molding process. It can be used as a reference in molding process. It can also be used to judge the actual injection process of specimen according to the peak cavity pressure.

\section{Conclusions}

An experimental work is carried out to study the effect of the microinjection molding parameters on the product weight in this paper. For the tensile and impact specimens, the packing pressure is the most important parameter affecting their weight. With the increase of packing pressure, the weight of both the tensile and impact specimens increases. The cavity pressure of impact specimen is larger than that of tensile specimen during injection molding because of unbalance filled. When the cavity pressure increases, the weight of the 


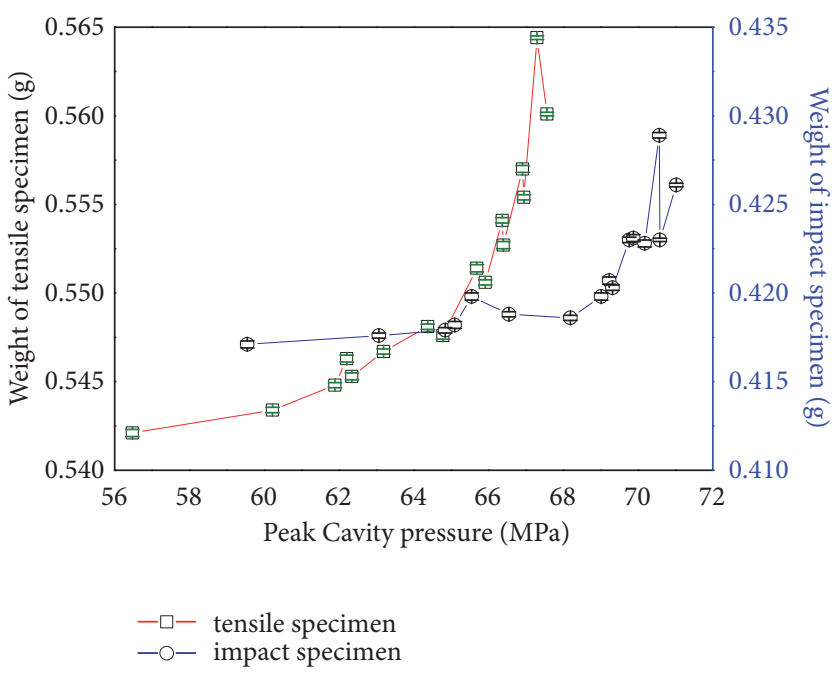

FIGURE 8: Effect of the peak cavity pressure on the tensile and impact specimen weight.

specimen will increase; when the peak cavity pressure reaches a certain value, the peak cavity pressure is about $65 \mathrm{MPa}$ for tensile specimen and peak cavity pressure is about $68 \mathrm{MPa}$ for impact specimen; when the peak cavity pressure increases, the weight of specimen increases significantly.

\section{Data Availability}

The data used to support the findings of this study are available from the corresponding author upon request.

\section{Conflicts of Interest}

The authors declared no potential conflicts of interest with respect to the research, authorship, and/or publication of this article.

\section{Acknowledgments}

The authors would like to acknowledge the financial support of the Excellent Young Talents Fund Program of Higher Education Institutions of Tianjin Province (RC180202), Research and Development Fund of Tianjin University of Technology and Education (KJ1808), and the National Natural Science Foundation of China (51403059) for financial support.

\section{References}

[1] M. Joglekar and B. G. Trewyn, "Polymer-based stimuliresponsive nanosystems for biomedical applications," Biotechnology Journal, vol. 8, p. 931, 2013.

[2] D. Ozdil and H. M. Aydin, "Polymers for medical and tissue engineering applications," Journal of Chemical Technology \& Biotechnology, vol. 89, no. 12, pp. 1793-1810, 2014.

[3] D. J. Phillips and M. I. Gibson, "Towards being genuinely smart: 'isothermally-responsive' polymers as versatile, programmable scaffolds for biologically-adaptable materials," Polymer Chemistry, vol. 6, pp. 1033-1043, 2015.
[4] G. Tosello, H. N. Hansen, and S. Gaspaparin, "Applications of dimensional micro metrology to the product and process quality control in manufacturing of precision polymer micro components," CIRP Annals - Manufacturing Technology, vol. 58, pp. 467-472, 2009.

[5] L. S. Nair and C. T. Laurencin, "Biodegradable polymers as biomaterials," Progress in Polymer Science, vol. 32, no. 8-9, pp. 762-798, 2007.

[6] K. M. Tsai and J. K. Lan, "Correlation between runner pressure and cavity pressure within injection mold," The International Journal of Advanced Manufacturing Technology, vol. 79, no. 1-4, pp. 273-284, 2015.

[7] X. D. Zhou, Y. Zhang, T. Mao, and H. M. Zhou, "Monitoring and dynamic control of quality stability for injection molding process," Journal of Materials Processing Technology, vol. 249, pp. 358-366, 2017.

[8] M. R. Kamal, R. El Otmani, A. Derdouri, and J. S. Chu, "Flow and thermal history effects on morphology and tensile behavior of poly(oxymethylene) micro injection molded parts," International Polymer Processing, vol. 32, no. 5, pp. 590-605, 2017.

[9] B. R. Whiteside, M. T. Martyn, P. D. Coates, P. S. Allan, P. R. Hornsby, and G. Greenway, "Micromoulding: process characteristics and product properties," Plastics, Rubber and Composites, vol. 32, no. 6, pp. 231-239, 2003.

[10] G. Tosello, H. N. Hansen, and S. Gasparin, "Applications of dimensional micro metrology to the product and process quality control in manufacturing of precision polymer micro components," Cirp Annals-Manufacturing Technology, vol. 58, p. 467, 2009.

[11] J. Q. Li, T. D. Li, Y. D. Jia, S. G. Yang, S. F. Jiang, and L. S. Turng, "Modeling and characterization of crystallization during rapid heat cycle molding," Polymer Testing, vol. 71, pp. 182-191, 2018.

[12] Y. Zhao, P. Zhao, J. F. Zhang, J. Y. Huang, N. Xia, and J. Z. Fu, "On-line measurement of clamping force for injection molding machine using ultrasonic technology," Ultrasonics, vol. 91, p. 170, 2018

[13] J. F. Zhang, P. Zhao, Y. Zhao, J. Y. Huang, N. Xia, and J. Z. $\mathrm{Fu}$, "On-line measurement of cavity pressure during injection 
molding via ultrasonic investigation of tie bar," Sensors and Actuators A: Physical, vol. 285, pp. 118-126, 2019.

[14] P. Zhao, W. M. Yang, X. M. Wang, J. G. Li, B. Yan, and J. $\mathrm{Z}$. Fu, "A novel method for predicting degrees of crystallinity in injection molding during packing stage," Proceedings of the Institution of Mechanical Engineers, Part B: Journal of Engineering Manufacture, vol. 233, no. 1, p. 204, 2019.

[15] A. Lopez, J. Aisa, A. Martinez, and D. Mercado, "Injection moulding parameters influence on weight quality of complex parts by means of DOE application: Case study," Measurement, vol. 90, pp. 349-356, 2016.

[16] Q. Zhang, H. Xu, D. M. Wu, and Z. W. Yang, "Experimental analysis on main technological parameters which influences the weight repeatability precision of injection molding products," Plastics, vol. 45, no. 6, pp. 107-109, 2016.

[17] W. W. Kim, M. G. Gang, B. K. Min, and W. B. Kim, "Experimental and numerical investigations of cavity filling process in injection moulding for microcantilever structures," The International Journal of Advanced Manufacturing Technology, vol. 75, no. 1-4, pp. 293-304, 2014.

[18] G. Gordon, D. O. Kazmer, X. Y. Tang, Z. Y. Fan, and R. X. Gao, "Quality control using a multivariate injection molding sensor," The International Journal of Advanced Manufacturing Technology, vol. 78, no. 9-12, pp. 1381-1391, 2015.

[19] J. P. Qu, B. S. Shi, and H. Z. He, "Influence of vibration on density of polymer solid granules in single screw extruder," PolymerPlastics Technology and Engineering, vol. 46, no. 3, pp. 233-237, 2007.

[20] C. Hopmann, A. Ressmann, and J. Heinisch, "Influence on product quality by pvT-optimised processing in injection compression molding," International Polymer Processing, vol. 31, no. 2, p. 156, 2016.

[21] X. J. Sun, X. M. Su, P. Tibbenham, J. H. Mao, and J. Tao, “The application of modified PVT data on the warpage prediction of injection molded part," Journal of Polymer Research, vol. 23, p. 86, 2016.

[22] T. Nguyen-Chung, C. Loser, G. Juttner, T. Pham, M. Obadal, and M. Gehde, "Simulation of the micro-injection moulding process: effect of the thermo-rheological status on the morphology," Proceedings of the Institution of Mechanical Engineers, Part E: Journal of Process Mechanical Engineering, vol. 225, p. 224, 2011.

[23] H. Hassan, "An experimental work on the effect of injection molding parameters on the cavity pressure and product weight," The International Journal of Advanced Manufacturing Technology, vol. 67, no. 1-4, pp. 675-686, 2013.

[24] M. Kurt, O. S. Kamber, Y. Kaynak, G. Atakok, and O. Girit, "Experimental investigation of plastic injection molding: Assessment of the effects of cavity pressure and mold temperature on the quality of the final products," Materials and Corrosion, vol. 30, no. 8, pp. 3217-3224, 2009.

[25] H. Zamani, S. Azmoudeh, and K. Shelesh-Nezhad, "Warpage characterization of thin and centrally-gated injection molded part by applying cavity pressure measurement," Applied Mechanics and Materials, vol. 446, pp. 1099-1103, 2014. 


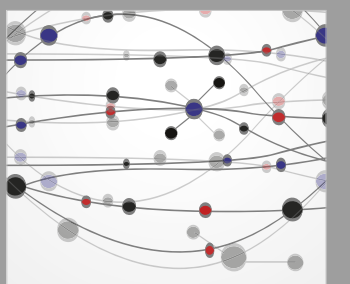

The Scientific World Journal
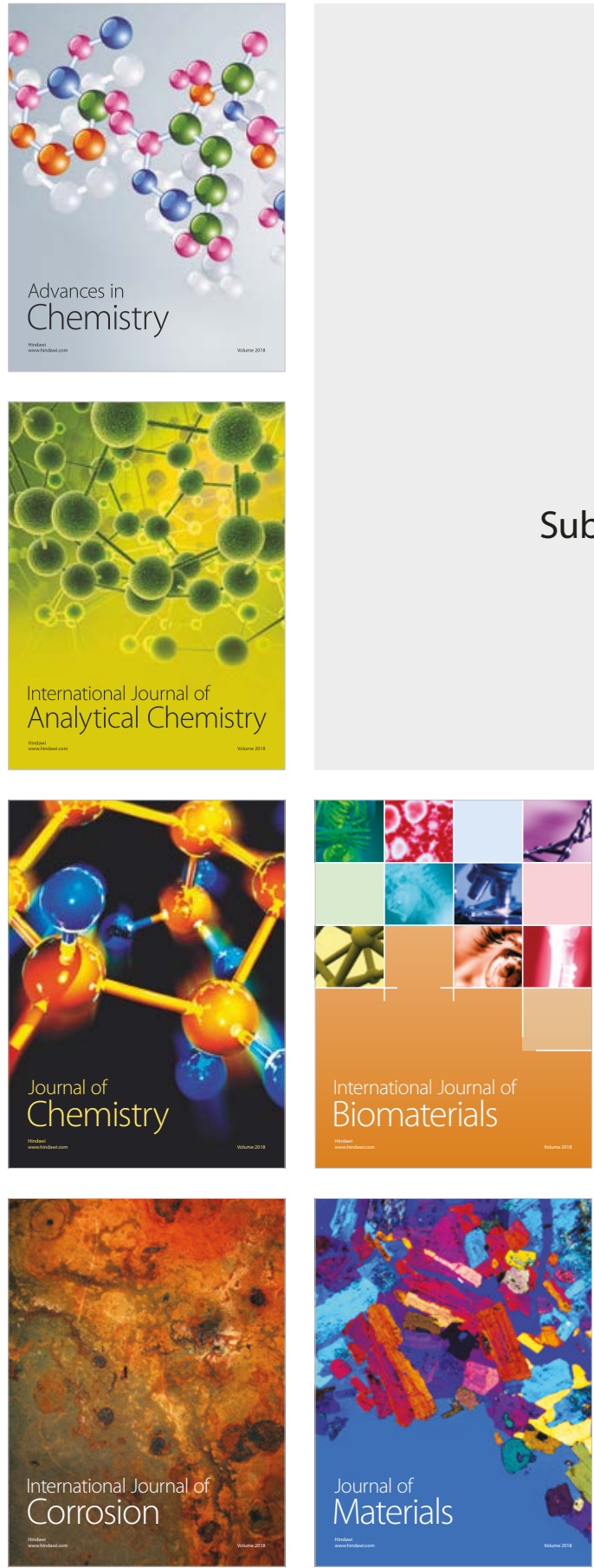

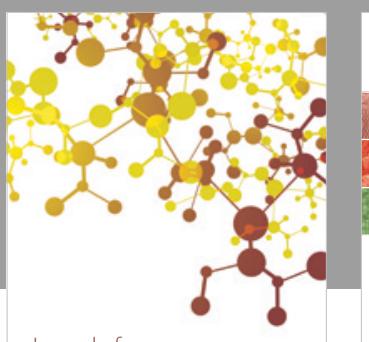

Journal of

Applied Chemistry
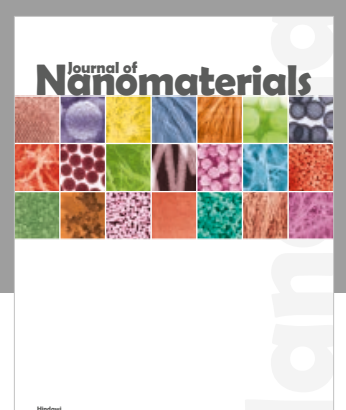

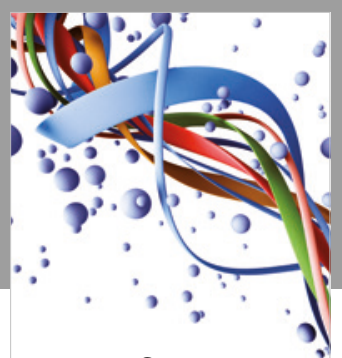

Scientifica

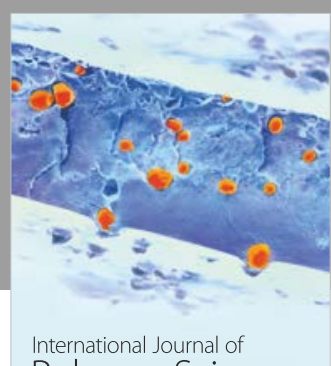

Polymer Science

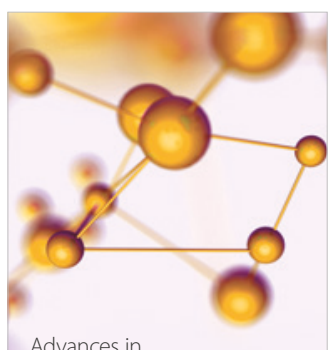

Physical Chemistry
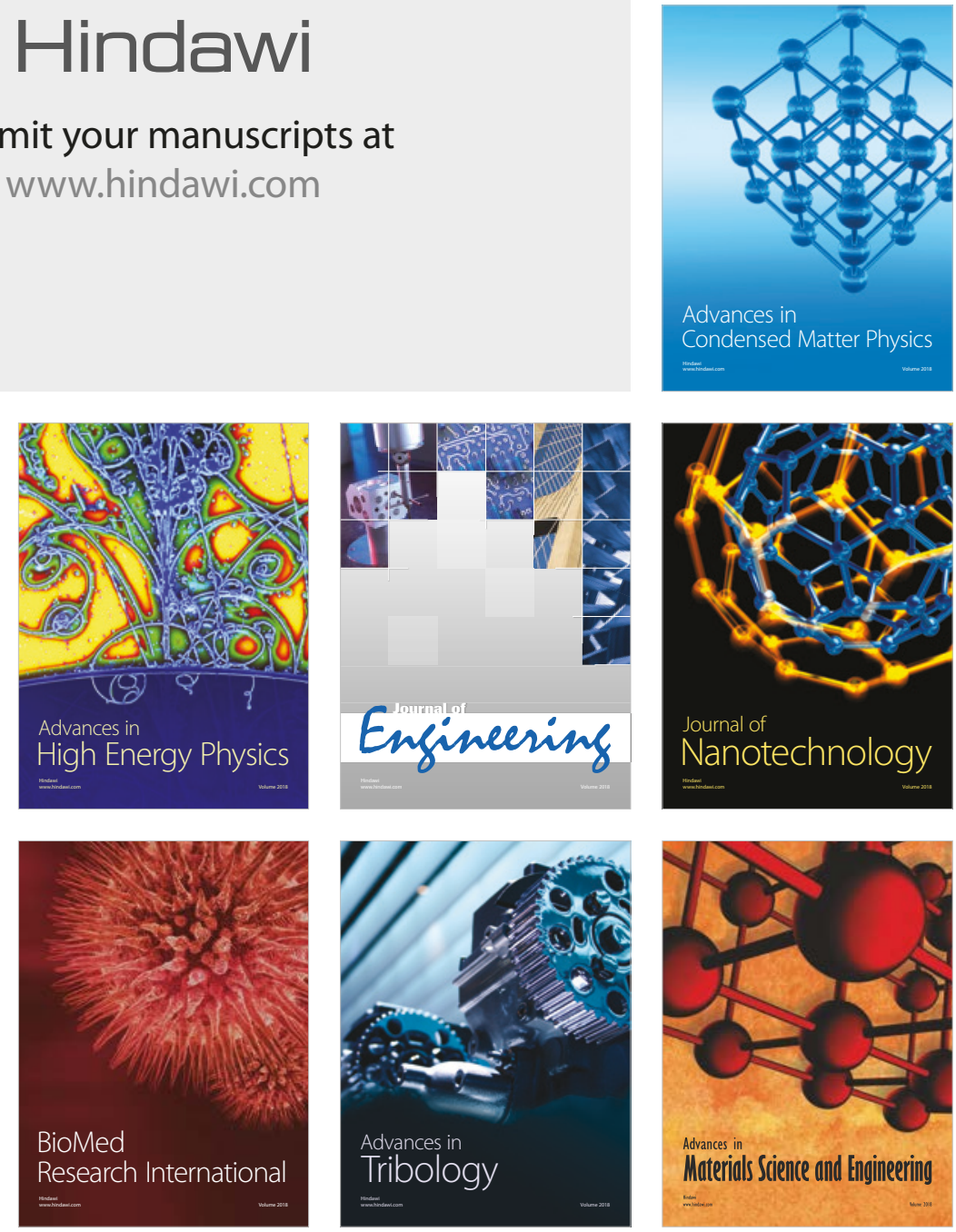